\title{
Lipid peroxidation, thiol groups, and total antioxidant capacity in mothers in natural vaginal delivery with and without Entonox: A cohort study
}

\author{
AKRAM RANJBAR ${ }^{1}$, KATAYON VAKILIAN ${ }^{2, *}$ \\ ${ }^{1}$ Department of Toxicology and Pharmacology, School of Pharmacy, Hamadan University of Medical Sciences, Hamadan, Iran \\ ${ }^{2}$ Medical School, Arak University of Medical Sciences, Arak, Iran \\ ${ }^{*}$ Corresponding author: Katayon Vakilian, PhD; Medical School, Arak University of Medical Sciences, Peiambar Azam Campus, Sardasht, \\ P.O. Box: 3848176941, Arak, Iran; Phone: +98 912324 9840; Fax: +98 34173 524; E-mail: dr.kvakilian@arakmu.ac.ir
}

(Received: April 4, 2018; Accepted: July 6, 2018)

\begin{abstract}
Background and objectives: Considering that very few studies have been conducted on the effect of Entonox on oxidative stress markers, this study was conducted to compare these markers in natural vaginal delivery (NVD) with and without Entonox. Materials and methods: The present cohort study was conducted on 120 women in maternity wards divided into two groups, including an NVD group with and an NVD group without Entonox. After obtaining the mothers' written consent, $5 \mathrm{cc}$ of venous blood was taken at the end of their second stage of labor for lipid peroxidation, thiol groups, and total antioxidant capacity tests. The data obtained were analyzed using descriptive (mean) and inferential ( $t$-test) statistics. Results: Lipid peroxide was $6.267 \pm 5.39$ in NVD without Entonox and 5.12 \pm 3.89 in NVD with Entonox, suggesting the lack of a statistically significant difference $(p=0.191)$. Thiol marker was $0.34 \pm 0.26$ in NVD without and $0.26 \pm 0.24$ in NVD with Entonox, suggesting the lack of a statistically significant difference $(p=0.09)$. The FRAP results were $0.936 \pm 0.696$ in NVD without and $1.21 \pm 0.89$ in NVD with Entonox, suggesting the lack of a statistically significant difference $(p=0.06)$. Discussion: Entonox can be safely used in NVD without increasing the risk of oxidative stress.
\end{abstract}

Keywords: oxidative stress, Entonox, natural vaginal delivery, total antioxidant capacity, lipid peroxidation, women

\section{Introduction}

Nitrous oxide gas is known as an anesthetic and antinociceptive, whose anesthetic effects are reduced and anti-nociceptive effects are increased when mixed with oxygen; the mixture of this gas with oxygen is known as Entonox. Entonox contains 50\% oxygen and 50\% nitrous oxide [1]. Despite the availability of other labor pain relief methods, Entonox is still one of the most widely used methods around for three reasons: it is fastacting and is rapidly cleared from the body, it does not require complex and expensive equipment or specialized personnel, and finally, it can be easily used by mothers [2]. Natural delivery is a stressful stage for the mother and fetus and may therefore lead to the phenomenon of oxidative stress and the high release of free radicals [3]. Oxidative stress is caused by the imbalance between the production of free radicals and reactive oxygen species on one hand, and antioxidant defense system on the other hand, and can have detrimental effects on the fetus if continued [4]. Labor pain and stress lead to the production of epinephrine and norepinephrine and thus results in the production of free radicals and thereby lipid peroxidation [5]. Entonox reduces labor pain by releasing endorphin [6]. This study examines the hypothesis that the pain relief caused by Entonox and the release of endorphins may lead to significantly different levels of oxidative stress markers in natural delivery compared to the delivery performed without pain relief.

This is an open-access article distributed under the terms of the Creative Commons Attribution-NonCommercial 4.0 International License, which permits unrestricted use, distribution, and reproduction in any medium for non-commercial purposes, provided the original author and source are credited, a link to the CC License is provided, and changes - if any - are indicated. 


\section{Materials and Methods}

The present cohort study was conducted on a sample of 120 women divided into a natural vaginal delivery (NVD) with Entonox group and an NVD without Entonox group. Each group consisted of 60 women selected through convenience sampling. Sampling was conducted at the labor ward of Taleghani Maternity Hospital (a referral center in Tehran) after obtaining permission from the hospital authorities as well as Arak University of Medical Sciences. Mothers admitted to this ward, who had no acute or chronic pregnancy complications, had a singleton term pregnancy, and had chosen their method of delivery themselves, were included in the study. After obtaining written informed consents from the mothers, $5 \mathrm{cc}$ of blood was taken from their brachial vein at the end of the second stage of labor in two groups. The blood samples were poured into heparinized tubes and transferred to the laboratory for freezing and centrifugal operations. After transferring the blood samples to the laboratory, their plasma was separated and tested for malondialdehyde (lipid oxidation) [7], thiol groups (protein oxidation) [8], and total antioxidant capacity (through ferric reducing ability of plasma) [9].

Two women were excluded from the NVD with Entonox group due to a significant drop in fetal heart rate and one due to the lack of labor progress; in the NVD group without Entonox, only one woman withdrew due to the lack of labor progress and therefore required cesarean section. Data were analyzed in SPSS-20 using descriptive (mean and frequency) and analytical ( $t$-test) statistics.

The women had a mean age of $22.83 \pm 0.52$ years in the NVD without Entonox group and $24.08 \pm 4.08$ years in the NVD with Entonox group, which does not indicate a statistically significant intergroup difference $(p=0.097)$. Their mean neonatal weight was $3,142 \pm 258 \mathrm{~g}$ in the NVD without Entonox group and 3,127 $\pm 245 \mathrm{~g}$ in the NVD with Entonox group, which shows the lack of a statistically significant difference between the groups $(p=0.785)$. The women's mean gestational age was $39.6 \pm 0.8$ weeks in the NVD with Entonox group and $39.2 \pm 0.06$ weeks in the NVD without Entonox group, which suggests no statistically significant differences between the groups $(p=0.727)$. The duration of the first stage of labor was $4.52 \pm 1.26 \mathrm{~h}$ in the NVD without Entonox group and $4.17 \pm 1.14 \mathrm{~h}$ in the NVD with Entonox group, showing no statistically significant intergroup differences. Table I presents the rest of the data obtained.

\section{Discussion}

The findings showed a higher lipid peroxidation in NVD without pain relief compared to NVD with pain relief, albeit not significantly. This finding may be caused by renewed tissue oxygenation during labor, which is induced by the mother's fear and anxiety in NVD and may affect oxidative stress markers $[4,5,10]$. The low level of lipid peroxidation in NVD with Entonox may be due to the induced pain relief $[1,6]$. A study conducted on the delivery process in mothers undergoing epidural anesthesia showed a lower lipid peroxidation induced by the destruction of the adipose tissue compared to cesarean section and natural childbirth [11]. The disparity of findings between this study and the other one discussed can be attributed to the pain relief methods used (Entonox in this study and epidural in the other). A study conducted by Vakilian and Ranjbar [12] on vaginal delivery with Entonox and cesarean section showed no significant changes in the amounts of lipid breakdown products (malondialdehyde) between the two methods, and the use of this gas was recommended due to the lack of significant differences in oxidative stress markers between the two methods. This study showed no significant differences between the two methods in the amounts of products from protein breakdown. The study by Vakilian et al. [13] on 60 mothers with NVD and 60 with elective cesarean section showed significantly more thiol molecules in NVD compared to elective cesarean section and thus recommended the reinforcement of antioxidant defense in mothers undergoing NVD before the onset of labor. This study showed that, although the antioxidant capacity was higher in NVD with Entonox, it was not significantly different from that in NVD without pain relief. A study conducted on 2,000 mothers undergoing cesarean section with epidural and general

Table I Lipid peroxidation, thiol groups, and total antioxidant capacity in mothers in NVD with and without Entonox

\begin{tabular}{llccr} 
Oxidative stress indices & \multicolumn{1}{c}{ Type of delivery } & Mean \pm SD & Confidence interval & $p$ value \\
Lipid peroxidation $(\mu \mathrm{M} / \mathrm{mm})$ & NVD (without Entonox) & $6.26 \pm 5.39$ & {$[-0.581,2.870]$} & 0.191 \\
& NVD (with Entonox) & $5.12 \pm 3.89$ & {$[-0.578,2.867]$} & 0.091 \\
Thiol $(\mu \mathrm{M} / \mathrm{mm})$ & NVD (without Entonox) & $0.34 \pm 0.26$ & {$[-0.130,0.173]$} & 0.062 \\
& NVD (with Entonox) & $0.26 \pm 0.24$ & {$[-0.013,0.173]$} & 0.062 \\
FRAP $(\mu \mathrm{M} / \mathrm{mm})$ & NVD (without Entonox) & $0.93 \pm 0.69$ & {$[-0.648,-0.012]$} & \\
& NVD (with Entonox) & $1.21 \pm 0.89$ & {$[-0.650,-0.011]$} &
\end{tabular}

SD: standard deviation; FRAP: ferric reducing ability of plasma; NVD: natural vaginal delivery 
anesthesia showed a reduced inhibition of enzymatic and vitamin antioxidant activity in the group of mothers with epidural [14]. Another study showed a lower total serum antioxidant in cesarean section compared to NVD. This marker is indicative of the protective capacity of tissues against the effects of reactive oxygen species [13]. It seems that reactive oxygen species increase in cesarean delivery due to the incidence of hypoxia during general anesthesia, thereby reducing the antioxidant capacity of the body [15].

\section{Conclusions}

The results obtained showed no significant differences between NVD with and NVD without pain relief in terms of oxidative stress markers. Considering its safety in terms of producing free radicals, Entonox can be used during labor. Further studies are recommended to be conducted on oxidative stress markers in other analgesic methods in mothers and infants. The limitations of this study include the lack of control over the amount of gas inhaled by the participants. Therefore, clinical trials are recommended to be conducted on the use of Entonox.

$$
\text { *** }
$$

Funding sources: Financial support was received by Arak University of Medical sciences by cod: 154 .

Authors' contribution: The idea of this research was carried out by Dr. $\mathrm{KV}$. The first draft article was written by Dr. AR, and the control of the translation and the second draft were done by KV. Also, all authors had full access to all data in the study and take responsibility for the integrity of the data and the accuracy of the data analysis.

Conflict of interest: There was no conflict of interest between the authors.

Acknowledgements: Hereby, the researchers would like to express their gratitude to the Research Deputy of Arak University of Medical Sciences for approving this project and also the mothers who participated in the study.

\section{References}

1. Riegels N, Richards MJ: Humphry Davy: His life, works, and contribution to anesthesiology. Anesthesiology 114, 1282-1288 (2011)

2. Collins MR, Starr SA, Bishop JT, Baysinger CL: Nitrous oxide for labor analgesia: Expanding analgesic options for women in the United States. Rev Obstet Gynecol 5, el26-e131 (2012)

3. Woods JR Jr, Cavanaugh JL, Norkus EP, Plessinger MA, Miller RK: The effect of labor on maternal and fetal vitamins C and E. Am J Obstet Gynecol 187, 1179-1183 (2002)

4. Vakilian K, Ranjbar A: Associations of oxidative stress indices in infants born via natural delivery with Entonox exposure. J Babol Univ Med Sci 17, 34-38 (2015)

5. Mehmetoúlu Ü, Kart A, Aúlayan O, Capar M, Gokec R: Oxidative stress in mothers and their new born in different type of labor. Turk Med Sci 32, 427-429 (2002)

6. Naddoni DB, Balakundi SK, Kammappa K: The effect of nitrous oxide (Entonox) on labour. Int J Reprod Contracept Obstet Gynecol 5, 835-839 (2016)

7. Satoh K: Serum lipid peroxide in cerebrovascular disorders determined by a new colorimetric method. Clin Chim Acta 90, 37-43 (1978)

8. Hu M, Diallard C: Plasma SH and GSH measurement. Methods Enzymol 233, 381-385 (1997)

9. Iris F, Benzi F, Strain S: Ferric reducing antioxidant assay. Methods Enzymol 299, 15-27 (1999)

10. Manouchehrian N, Bakhshaei MH: Nitrous oxide effect on relieving anxiety and pain in parturients under spinal anesthesia for caesarean section. Anesthesiol Pain Med 4, el6662 (2014)

11. Kart A, Calayan O, Capa R: Oxidative stress in mothers and their new born in different type of labor. Turkish Med Sci 32, 427-429 (2002)

12. Vakilian K, Ranjbar A: Oxidative stress indices in mothers and newborns born through cesarean section compared to vaginal delivery inhaling Entonox. IJW HR Bio Senses (2018)

13. Vakilian K, Ranjbar A, Zarganjfard A, Mortazavi M, VosoughGhanbari S, Mashaiee S, Abdollahi MN: The relation of oxidative stress in delivery mode in pregnant women; a toxicological concern. Toxicol Mech Methods 19, 94-99 (2009)

14. Nakai A, Oya A, Kobe H, Asakura H, Yokota A, Koshino T, Araki T: Changes in maternal lipid peroxidation levels and antioxidant enzymatic activities before and after delivery. J Nippon Med School 67, 434-439 (2000)

15. Burlingame JM, Esfandiari N, Sharma RK, Mascha E, Falcone T: Total antioxidant capacity and reactive oxygen species in amniotic fluid. Obstet Gynecol J 1, 756-761 (2003) 